\title{
Magnetic Characterization of Ferromagnetic Alloys for High-Speed Electric Machines
}

\author{
Chetan Urabinahatti ${ }^{\circledR}$, Syed Shahjahan Ahmad ${ }^{\circledR}$, and Gopalaratnam Narayanan
}

\begin{abstract}
High-speed electric machines operate at tens of thousands of revolutions per minute. The rotor and stator cores experience high-frequency electromagnetic fields. While the magnetic characteristics are available at $50 / 60 \mathrm{~Hz}$, magnetic characteristics are required over a wide range of frequency due to variable speed operation of high speed motor. In this article, tests are carried out on ferromagnetic alloys over a frequency range of $1 \mathrm{~Hz}$ to $5 \mathrm{kHz}$ and flux densities ranging from 0.1 to $2 \mathrm{~T}$. The materials considered include the widely used M36 and $65 \mathrm{C600}$ laminations. In applications where the rotor speed and shaft temperature are high, solid core rotors are more viable than laminated ones. Furthermore, the application requires that the shaft and active magnetic parts of the rotor be made of a single material. Hence, EN353 and EN8 are the prospective rotor materials considered. An extensive experimental study on the magnetic characteristics of these materials over a wide frequency range is reported in this article. The flux density variation over the core length at different frequencies is analyzed using finite element analysis. The results include B-H curves, static magnetisation curves, and power loss curves. The loss curves are useful to evaluate the loss density in the magnetic material at different frequencies and for various values of peak flux densities. These experimental data are essential for the analysis, design, and performance evaluation of high-speed electric machines.
\end{abstract}

Index Terms-B-H measurement, loss curve, magnetic material, static magnetisation curve.

\section{INTRODUCTION}

$\mathbf{H}$ IGH-SPEED electric machines are used for different applications such as compressors, gas turbines, blowers, and machining spindles [1], [2]. Design of high-speed machines is a multidisciplinary problem, where in multiphysics simulation is often resorted to [3]. The main challenges include noise and vibrations [4], rotor deformations at high speeds [5] and temperature rise [6]. Measurement techniques for research on noise and vibrations are described in [7]. A low-cost acoustic

Manuscript received November 24, 2019; revised June 27, 2020; accepted September 5, 2020. Date of publication September 14, 2020; date of current version November 19, 2020. Paper 2019-EMC-1329.R1, presented at the 2018 IEEE International Conference on Power Electronics, Drives, and Energy Systems, Chennai, India, Dec. 18-21 and approved for publication in the IEEE TRANSACTION ON INDUSTRY APPLICATION by the Energy Systems Committee of the IEEE industry Applications Society. This work was supported by the Ministry of Human Resources Development and the Ministry of Power, Government of India, under an IMPRINT project titled "Design, Development and Control of High-Speed Switched Reluctance Generator for Direct-Coupled Operation with Thermal Turbo-Machinery." (Corresponding author: Chetan Urabinahatti.)

The authors are with the Department of Electrical Engineering, Indian Institute of Science, Bangalore, Bengaluru 560012, India (e-mail: chetansureshu@gmail.com; ssa.2048@gmail.com; gnar@iisc.ac.in).

Color versions of one or more of the figures in this article are available online at https://ieeexplore.ieee.org.

Digital Object Identifier 10.1109/TIA.2020.3023868 noise measurement technique [8] and structural characterization of machine based on noise measurements [9] have been reported. Structural studies for prediction of vibration and rotor deformation at high speeds have also been reported recently [10].

Temperature rise is another important challenge. Hightemperature operation brings in special requirements on the magnetic material to be used [11]. Study of temperature rise requires detailed thermal analysis [6], [12]. An important reason for temperature rise is the loss in magnetic materials that form the stator as well as rotor. These core losses strongly influence the performance and efficiency of the machines [13], [14]. Loss estimation in magnetic materials [15] and electric machines [16]-[18] utilizes the properties of the magnetic material, which are the focus of this article.

Performance evaluation and design optimization of an electric machine requires precise knowledge of the properties of magnetic material used to build its stator and rotor. Literature exists on characterization of different magnetic materials [19][21]. Various types of ferromagnetic alloys are available in the market which carry names such as M36, M19, M22, 65C600, 25CS1250HF, and JNEX [22], [23]. These alloys have different amount of silicon content, which affects characteristics [24]. There are also other magnetic materials such as amorphous soft magnetic materials which provide higher efficiency [25] but have limitation on mechanical processing. The impact of manufacturing processes on magnetic properties is discussed in [26]-[28].

The magnetic properties of materials vary with the excitation frequency. This frequency varies widely on account of the wide range of operating speeds of a variable speed motor drive. The impact of stator and rotor magnetic materials on variable speed operation is discussed in [29]. The range of frequency is still wider and the highest frequency is much higher in a high-speed machine drive than in a conventional variable speed drive. The high-speed machines are designed to operate at speeds in the order of tens of thousands of revolution per minute [1]. The magnetic material in such machines experience high-frequency electromagnetic fields at high speed. Most often, datasheets of manufacturers provide loss data at 50 or $60 \mathrm{~Hz}$ only [23]. In some cases [30] power loss data are available up-to $400 \mathrm{~Hz}$. For high speed motor drives it is necessary to know the magnetic characteristics and loss data at still higher frequencies. The widely used M36 and 65C600 laminations are tested over a wide frequency range $(1 \mathrm{~Hz}$ to $5 \mathrm{kHz})$ in this article.

In certain high-speed and high-temperature application, the rotor made up of lamination could experience structural 
deformation. Further the glue and insulating material in the laminates might not be able to withstand high temperatures. There is significant expansion at high temperatures. To avoid possible problems due to different thermal coefficients of the shaft and the magnetic part of the rotor, the same material could be preferably used as shaft as well as rotor [31]. A solid rotor could be one of the few viable option in high-speed, high-temperature and/or corrosive environment [31], [32]. Being machined from a single material, solid rotor can withstand higher mechanical stress, have lower mass unbalance and higher critical speed than laminated rotor [31]. The material used should have a good mix of mechanical strength and magnetic properties. Alloys such as EN8 and EN353 are reasonable options in this regard. The magnetic properties of these materials need to be studied under wide range of excitation conditions, as reported in this article.

It is important that the knowledge of the magnetic properties of the core material are captured adequately into equivalent circuit modeling of the machine winding to aid performance evaluation of the electric machine [33]. Typically, the magnetic properties are included in the equivalent circuit as a magnetizing inductance, representing core magnetization, along with a parallel resistive branch, accounting for core-loss [33], [34]. In most cases core-loss is modeled by a fixed resistance in the equivalent circuit [31], [33], [35]. However, this results in poor modeling accuracy when the machine is experiencing large core loss and saturation [31], [35]. A variable core-loss resistance and magnetizing inductance model, having good accuracy, is proposed in [33]. Apart from current-dependence, variations of core-loss resistance and magnetizing inductance with frequency are incorporated into the modeling approach in [31], which further improves accuracy and is also computationally efficient. However, these recent works require extensive experiments on the actual machine winding to determine the equivalent circuit parameters accurately. This article attempts to extend the technique in [31] to determine the winding equivalent circuit by utilizing the magnetic characteristics (measured over a wide operating range) of the material rather than measurements on the machine winding.

The magnetic properties of five different ferromagnetic alloys are measured using the technique reported in [19]. Voltage and current waveforms are measured at various excitation conditions on each sample. The sample preparation (core dimensions and windings) ensures reasonable uniformity in flux density inside the core, low leakage field, and good coupling between the core and sensing coil. The experimental procedure ensures sinusoidal variation of core flux density at the specified frequency. The measured voltage and current waveforms are utilized to obtain $\mathrm{B}$ versus $\mathrm{H}$ loops with peak flux densities as low as $0.1 \mathrm{~T}$ to as high as $2 \mathrm{~T}$, over $1 \mathrm{~Hz}$ to $5 \mathrm{kHz}$ frequency range, for the different materials. Three-dimensional finite element analysis (FEA) is also carried out for the solid core materials to better understand and interpret the experimental results obtained at higher frequencies. Static magnetization and loss curves are presented for all the materials considered. Furthermore, the experimental data are used to derive frequency-dependent magnetization and loss characteristics of magnetic materials, which

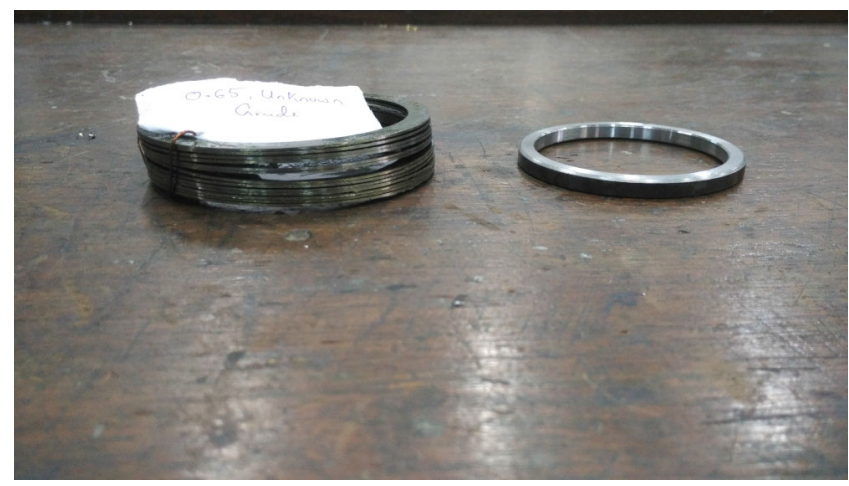

Fig. 1. Images of laminations and solid core.

TABLE I

Magnetic Materials AND TOROIDAL CORE DimEnSions

\begin{tabular}{|c|c|c|c|c|}
\hline S.No & Material & $\mathrm{OD}(\mathrm{mm})$ & $\mathrm{ID}(\mathrm{mm})$ & Area $\left(\mathrm{mm}^{2}\right)$ \\
\hline 1 & M36 & 100 & 90 & 24.5 \\
\hline 2 & EN353-Hardened & 100 & 90 & 25 \\
\hline 3 & EN353-Non Hardened & 100 & 90 & 25 \\
\hline 4 & 65 C600 & 86.5 & 73.7 & 33.28 \\
\hline 5 & EN8 & 70 & 60 & 25 \\
\hline
\end{tabular}

can be used to derive the equivalent circuit of winding on a magnetic structure. A preliminary version of this work was presented in a conference [36]. Further results, detailed analyses and discussions are reported in this journal version.

\section{Methodology}

The geometry of the test samples and the testing procedure are discussed in this section.

\section{A. Core Geometry}

The magnetic core material under test can be either toroidal in shape or a rectangular strip. In case of rectangular strips, the flux density at the corners is not uniform and also there are small air gaps at the junctions. Hence, this work uses toroid shaped cores which have uniform cross section and have no air gap. The flux density can be considered to be reasonably uniform. (Cases of nonuniform flux density distribution in solid cores at high frequencies are reported in Section IV-B.) Fig. 1 presents a photograph showing toroidal laminations and a solid toroidal core. The M36 and 65C600 laminations have thicknesses of 0.35 and $0.65 \mathrm{~mm}$, respectively. The laminations are stacked for a height of $5 \mathrm{~mm}$ for the purpose of tests here. The hardened EN353 (hardened to 50 Rockwell Hardness scale C), nonhardened EN353 and EN8 are the solid cores considered as mentioned earlier. The solid cores are also of height $5 \mathrm{~mm}$. The outer diameter (OD), inner diameter (ID), and cross-sectional areas of the toroids are indicated in Table I. The ratio of OD to ID is kept low (1.1 to 1.17), which improves uniformity of magnetic field inside the core [37], [38]. 
TABLE II

DETAILS OF SAMPLES TESTED

\begin{tabular}{|c|c|c|c|}
\hline S.No & Sample Name & Material & $N_{p}=N_{s}$ \\
\hline 1 & S1 & M36 & 500 \\
\hline 2 & S2 & M36 & 50 \\
\hline 3 & S3 & EN353 Non-Hardened & 500 \\
\hline 4 & S4 & EN353 Non-Hardened & 50 \\
\hline 5 & S5 & EN353 Hardened & 500 \\
\hline 6 & S6 & EN353 Hardened & 200 \\
\hline 7 & S7 & $65 C 600$ & 500 \\
\hline 8 & S8 & EN8 & 300 \\
\hline
\end{tabular}

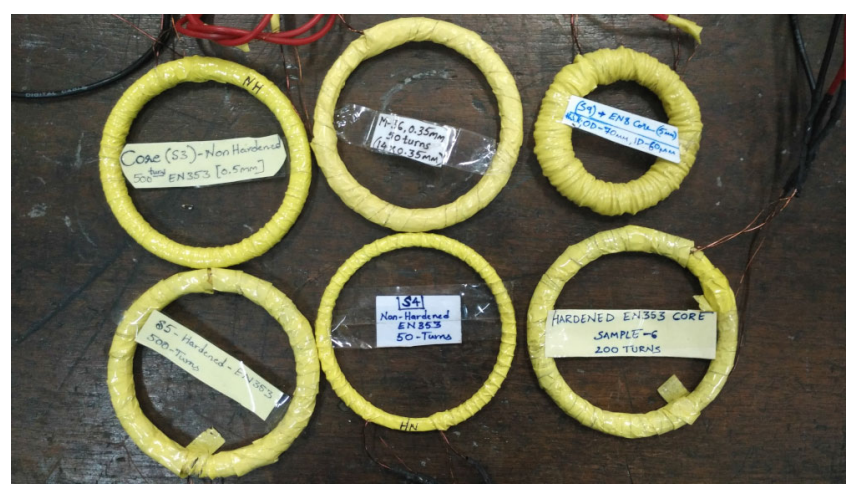

Fig. 2. Images of the tested toroidal cores. Clock wise (from top left): S3, S2, S8, S6, S4, and S5.

\section{B. Test Samples}

A secondary winding of $N_{s}$ turns of wire gauge SWG24 is wound over the toroidal solid core or lamination stack, as the case may be, with an insulation layer of $0.36 \mathrm{~mm}$ thickness in between. The primary coil of $N_{p}$ turns of SWG19 gauge wire is wound over the secondary with another $0.36 \mathrm{~mm}$ thick insulation layer in between. Here, $N_{p}$ is equal to $N_{s}$. Since the induced voltage across the secondary winding is to be measured, the secondary is kept closer to the core for good coupling between this coil and the field inside the core [38]. A total of eight number of samples are prepared, as detailed in Table II, for the experimental study. The images of six of these samples are shown in the photograph in Fig. 2.

\section{Analysis of Leakage Field}

For typical excitation of the primary coil, the energy in the leakage field is estimated and found to be low for the different samples using a classical method of analysis [39] and also finite element (FE) analysis. In case of sample S1 (material M36, 500 turns, relative permeability of 3538 at $0.5 \mathrm{~T}$ ), the analytically estimated energy in leakage field [39] is only $0.063 \%$ of the energy stored in the core. For the same case, the leakage is estimated to be $0.061 \%$ using FEA. The leakage is expected to be higher when the core permeability is lower [39]. The leakage is estimated to be quite low even for sample S8 (material EN8, 300 turns, relative permeability 468), which is an example for low core permeability; the leakage is $0.47 \%$ and $0.45 \%$, respectively,

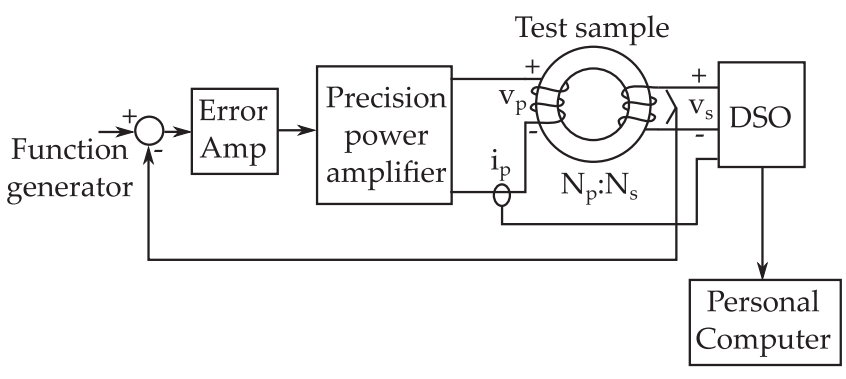

Fig. 3. Block diagram of the experimental setup.

as estimated by the analytical [39] and FE methods. Hence, the effect of leakage is neglected in the experimental studies.

\section{Sinusoidal Flux Density Variation}

During the experiments, the variation of core flux density is ensured to be sinusoidal, and of the desired frequency, using the closed-loop structure indicated by Fig. 3. The error between the measured secondary voltage and the sinusoidal reference voltage is fed to an error amplifier. The error amplifier provides input to a precision power amplifier which, in turn, feeds the primary winding of the test sample.

\section{E. Details of Experimental Setup}

The input sinusoidal reference signal is provided by a function generator (Keysight $33521 \mathrm{~A}, 30 \mathrm{MHz}$ bandwidth, total harmonic distortion $(\mathrm{THD})<0.04 \%$ ). The precision power amplifier used is a novel transformer-less power amplifier rated at $70 \mathrm{~V}$ (peak voltage) and $10 \mathrm{~A}$ (peak current). This is a direct-coupled, multistage, linear amplifier, having a high small-signal bandwidth of $65 \mathrm{kHz}$ and very low dc offset $(<0.2 \mathrm{mV})$. The primary current $i_{p}$ is measured by a Tektronix current probe (TCP312 A, dc-100 MHz bandwidth, 0-30 A current, 1\% accuracy). The secondary voltage $v_{s}$ is measured by a Tektronix passive voltage probe (P2220, $200 \mathrm{MHz}$ bandwidth). A Tektronix DPO2024B digital storage oscilloscope (DSO) is used to capture the waveforms. The DSO has bandwidth of $200 \mathrm{MHz}$, sampling rate of $1 \mathrm{GS} / \mathrm{s}$, vertical resolution of $8 \mathrm{~b}$ and dc gain accuracy of $3 \%$. An average of 128 waveforms, having record length of 125000 points, is captured in the DSO, and transferred to a personal computer for further storage and processing.

\section{F. Experimental Procedure}

A sinusoidal voltage is applied to the reference input of the error amplifier. The primary current $i_{p}$ and the secondary induced voltage $v_{s}$ are measured. As suggested by (1) below

$$
v_{s}=N_{s} A \frac{d B}{d t}
$$

the integral of the measured $v_{s}$ (or the flux linkage of the secondary coil) is divided by the number of turns $N_{s}$ and core cross-sectional area $A$ to obtain the (average) time-varying flux density $B(t)$ in the core. The primary current $i_{p}$ is multiplied by 


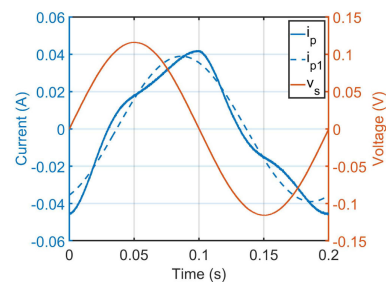

(a)

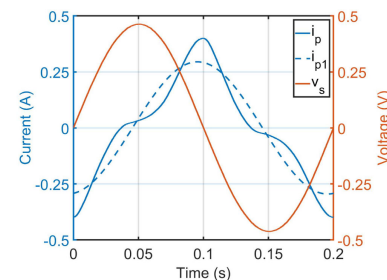

(b)

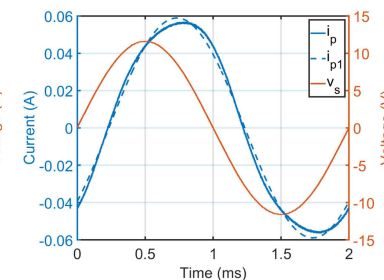

(c)

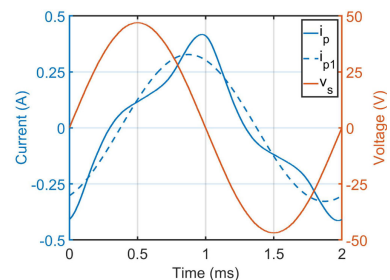

(d)

Fig. 4. Measured $v_{s}$ and $i_{p}$ waveforms for M36 lamination. Dotted line shows fundamental component $i_{p 1}$ of current $i_{p}$. (a) $f=5 \mathrm{~Hz}, B_{p k}=0.3 \mathrm{~T}$. (b) $f=5 \mathrm{~Hz}, B_{p k}=1.2 \mathrm{~T}$. (c) $f=500 \mathrm{~Hz}, B_{p k}=0.3 \mathrm{~T}$. (d) $f=500 \mathrm{~Hz}, B_{p k}=1.2 \mathrm{~T}$. THD in $v_{s}$ waveforms are (a) $0.4 \%$. (b) $0.53 \%$. (c) $0.35 \%$. (d) $0.28 \%$. The fundamental inductive power factor angles are (a) $65.2^{\circ}$. (b) $81.4^{\circ}$. (c) $42^{\circ}$. (d) $67.4^{\circ}$.

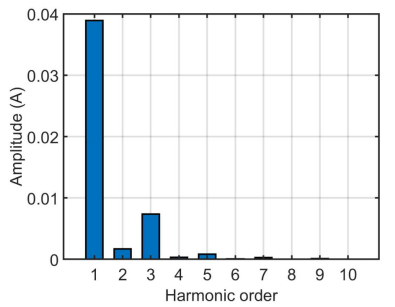

(a)

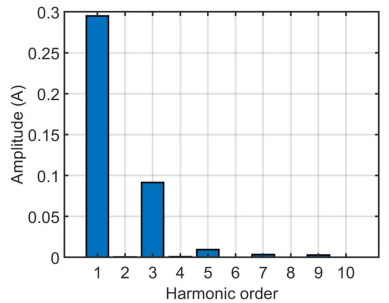

(b)

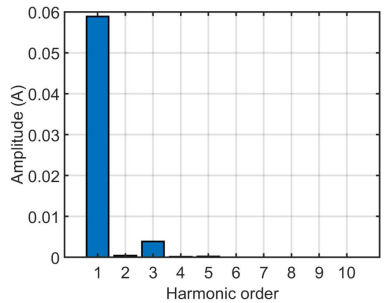

(c)

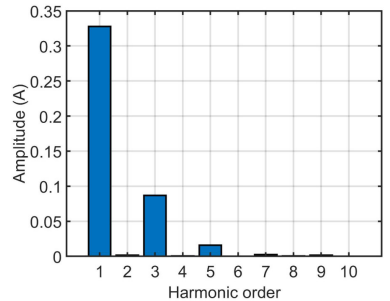

(d)

Fig. 5. Harmonic spectra of measured $i_{p}$ waveforms for M36 laminations. (a) $f=5 \mathrm{~Hz}, B_{p k}=0.3 \mathrm{~T}$. (b) $f=5 \mathrm{~Hz}, B_{p k}=1.2 \mathrm{~T}$. (c) $f=500 \mathrm{~Hz}, B_{p k}=0.3 \mathrm{~T}$. (d) $f=500 \mathrm{~Hz}, B_{p k}=1.2 \mathrm{~T}$.

a factor of $N_{p} / l_{m}$ to obtain $H(t)$ as shown

$$
H(t)=i_{p} \frac{N_{p}}{l_{m}}
$$

where $l_{m}$ is the mean length of magnetic path through the core.

The abovementioned procedure is repeated with different input voltages and frequencies to obtain the magnetic characteristics at different values of peak flux density $B_{p k}$ and frequencies.

\section{G. Static Magnetisation and Loss Characteristics}

The peak flux density $B_{p k}$ and the corresponding peak magnetizing force $H_{p k}$ values obtained at $1 \mathrm{~Hz}$ input excitation frequency for different excitation voltage levels are joined together to obtain the static magnetization curve. To obtain the power loss density at different frequency and peak flux density values, the average power loss $P_{l}$ is obtained first as follows:

$$
P_{l}=\frac{1}{T} \int_{0}^{T} v_{s} i_{p} d t
$$

The loss density $P_{d}$ is obtained as follows:

$$
P_{d}=\frac{P_{l}}{m_{s}}=\frac{P_{l}}{\rho V}
$$

where $m_{s}$ is mass of the toroid sample, $V$ is volume of the toroid, and $\rho$ is the material density.

\section{EXPERIMENTAL VOLTAGE AND CURRENT WAVEFORMS}

The measured primary current $i_{p}$ and secondary induced voltage $v_{s}$ for different cores are presented in this section. Harmonic spectrum of $i_{p}$ is also reported in each case.

\section{A. Laminated Core}

Fig. 4(a) and (b) shows the measured $v_{s}$ and $i_{p}$ from sample S1 (M36 lamination, 500 turns) at low frequency of 5 Hz. Fig. 4(c) and (d) presents waveforms from the same sample S1 at a higher excitation frequency of $500 \mathrm{~Hz}$. The closed-loop action in the amplifier ensures that the induced voltage $v_{s}$ is quite sinusoidal in all cases, indicating the variation in core flux density to be sinusoidal. The harmonic spectra of the measured $i_{p}$ waveforms in Fig. 4(a)-(d) are presented in Fig. 5(a)-(d), respectively.

As seen from Figs. 4(c) and 5(c), $i_{p}$ is least distorted at low flux density $B_{p k}=0.3 \mathrm{~T}$ and high frequency of $500 \mathrm{~Hz}$. At low frequency of $5 \mathrm{~Hz}$, the current is quite distorted (though not much peaky) for $B_{p k}$ of $0.3 \mathrm{~T}$ [see Figs. 4(a) and 5(a)]. This suggests nonlinearity close to the origin in the B-H curve. At high $B_{p k}$ of $1.2 \mathrm{~T}$, the currents are peaky, as shown by Fig. 4(b) and (d), suggesting magnetic saturation; the distortion is quite high [see Fig. 5(b) and (d)].

The measured $v_{p}$ is not shown in Fig. 4(a)-(d), but is quite close to $v_{s}$, since the turns ratio is one and resistive drop in primary coil is negligible. The fundamental component $i_{p 1}$ of primary current $i_{p}$ is indicated by dotted lines in Fig. 4(a)-(d). The lagging power factor angles of $i_{p 1}$ are indicated in the figure caption. At high $B_{p k}(1.2 \mathrm{~T})$ and low frequency $(5 \mathrm{~Hz})$, the magnetizing branch current is quite high and core loss branch current is low; consequently, the lagging power factor angle is close to $90^{\circ}$ (actually $81.4^{\circ}$ ) in Fig. 4(b). On the other hand, at low $B_{p k}(0.3 \mathrm{~T})$ and high frequency $(500 \mathrm{~Hz})$, the magnetizing component is low and the core loss component is significant; hence, the lagging power factor angle is quite low $\left(42^{\circ}\right)$ in Fig. 4(c). 


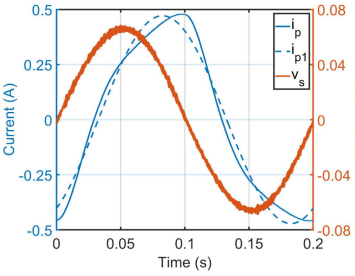

(a)

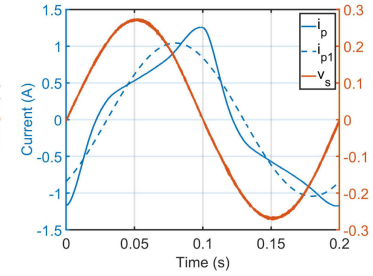

(b)

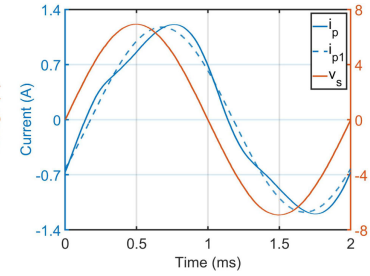

(c)

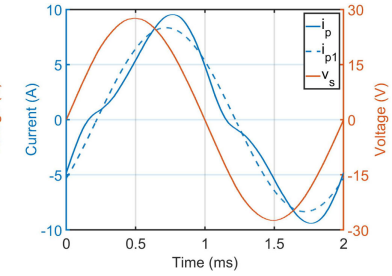

(d)

Fig. 6. Measured $v_{s}$ and $i_{p}$ waveforms for EN8 solid core. Dotted line shows fundamental component $i_{p 1}$ of current $i_{p}$. (a) $f=5 \mathrm{~Hz}, B_{p k}=0.3 \mathrm{~T}$. (b) $f=5 \mathrm{~Hz}$, $B_{p k}=1.2 \mathrm{~T}$. (c) $f=500 \mathrm{~Hz}, B_{p k}=0.3 \mathrm{~T}$. (d) $f=500 \mathrm{~Hz}, B_{p k}=1.2 \mathrm{~T}$. THD in $v_{s}$ waveforms are (a) $2.8 \%$. (b) $1.7 \%$. (c) $0.46 \%$. (d) $0.8 \%$. The fundamental inductive power factor angles are (a) $56.3^{\circ}$. (b) $52.4^{\circ}$. (c) $32.1^{\circ}$. (d) $40.1^{\circ}$.

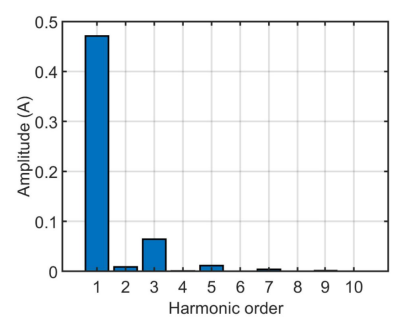

(a)

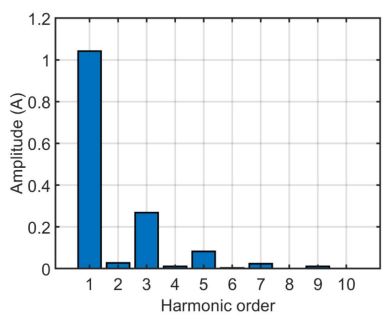

(b)

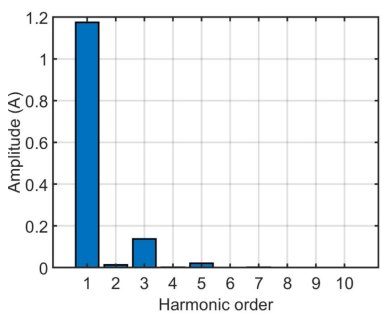

(c)

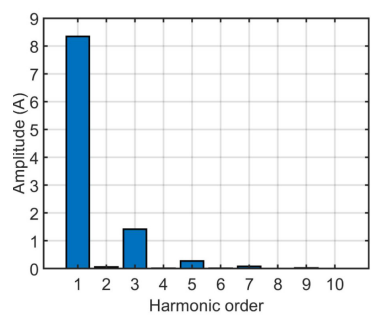

(d)

Fig. 7. Harmonic spectra of measured $i_{p}$ waveforms for EN8 solid core. (a) $f=5 \mathrm{~Hz}, B_{p k}=0.3 \mathrm{~T}$. (b) $f=5 \mathrm{~Hz}, B_{p k}=1.2 \mathrm{~T}$. (c) $f=500 \mathrm{~Hz}, B_{p k}=0.3 \mathrm{~T}$. (d) $f=500 \mathrm{~Hz}, B_{p k}=1.2 \mathrm{~T}$.

\section{B. Solid Core}

The measured $v_{s}$ and $i_{p}$ waveforms from sample $\mathrm{S} 8$, made out of solid core EN8 and having 300 turns, are shown in Fig. 6(a)-(d) for the same $B_{p k}$ values and excitation frequencies as in Fig. 4(a)-(d). Though the THD values of the induced voltage $v_{s}$ in Fig. 6(a)-(d) are slightly higher than the corresponding values in Fig. 4(a)-(d), these induced voltages are still very much sinusoidal, confirming that the flux density variation in the solid core is also sinusoidal.

For the same values of $B_{p k}$ and frequency, the primary current $i_{p}$ drawn by the solid core sample (Fig. 6) is much higher than that by M36 lamination (Fig. 4). The waveform of $i_{p}$ is typically distorted, but is much less peaky than in case of laminated core. Hence, typically, one can identify four sections in each cycle of $i_{p}$; the shape of $i_{p}$ is roughly constant in each of these sections. The harmonic spectra of the measured $i_{p}$ waveforms in Fig. 6(a)-(d) is provided in Fig. 7(a)-(d), respectively.

The fundamental component $i_{p 1}$ is shown in dotted lines in Fig. 6(a)-(d). The lagging power factor angles are also indicated in the caption of Fig. 6. These lagging angles are all much lower than $90^{\circ}$ (actually ranging between $56.3^{\circ}$ and $32.1^{\circ}$ ). Even in the case of high $B_{p k}$ and low frequency [Fig. 6(b)], this angle is only $52.4^{\circ}$. This suggests that, in general, the core loss component of the current $i_{p}$ is quite dominant in this solid core.

\section{Measured B-H LOOPS}

The measured B-H loops pertaining to five different magnetic materials at different frequencies and for various peak flux densities are reported in this section.

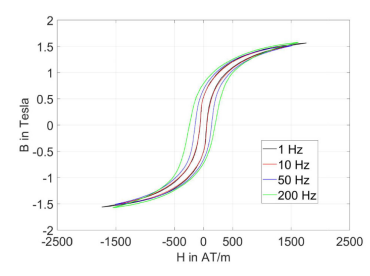

(a)

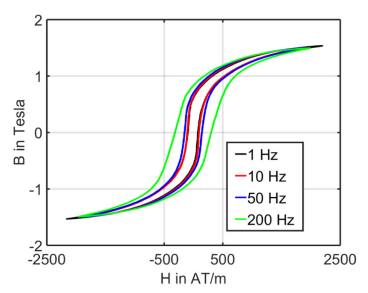

(b)
Fig. 8. B-H loops for $B_{p k}=1.5 \mathrm{~T}$ at different frequencies for laminations. (a) M36. (b) 65C600.

\section{A. Laminated Cores}

Using the measured $v_{s}$ and $i_{p}$ waveforms, the $\mathrm{B}-\mathrm{H}$ loops are obtained for M36 and 65C600 laminations at different values of $B_{p k}$ and various frequencies. These loops for $B_{p k}=1.5 \mathrm{~T}$ and different frequencies ranging from 1 to $100 \mathrm{~Hz}$ for M36 and 65C600 laminations are shown in Fig. 8(a) and (b), respectively. These B-H loops are thin, indicating that the core losses are low, as should be expected for laminated cores. The loops are almost flat and horizontal at the top and bottom, indicating high degree of saturation above $1 \mathrm{~T}$, and correlating well with the peaky magnetizing currents drawn. For the same $B_{p k}$ of $1.5 \mathrm{~T}$, the $H_{p k}$ is higher for $65 \mathrm{C} 600$ than for M36 as shown by Fig. 8(a) and (b).

The B-H loops for different values of $B_{p k}$ at the same frequency of $50 \mathrm{~Hz}$ are presented in Fig. 9(a)-(b) for M36 and $65 \mathrm{C} 600$, respectively. Clearly, the loop areas are much longer for 65C600 than M36, indicating significantly higher loss when $65 \mathrm{C} 600$ is used. 


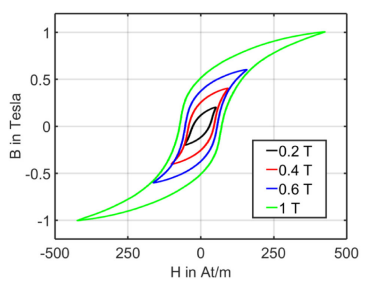

(a)

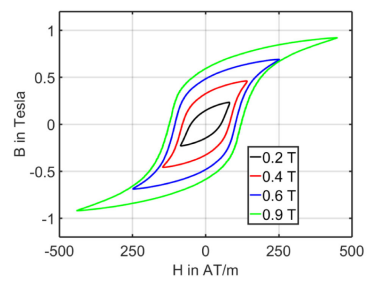

(b)
Fig. 9. B-H loops at $f=50 \mathrm{~Hz}$ for different $B_{p k}$ values for laminations. (a) M36. (b) 65C600.

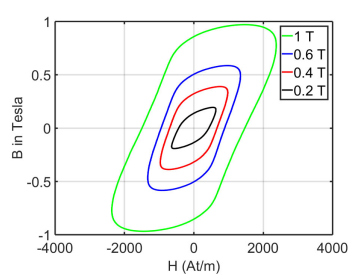

(a)

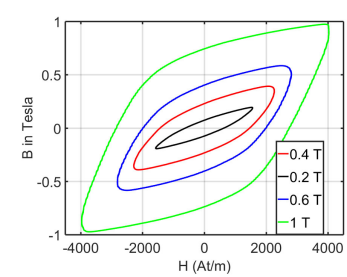

(b)

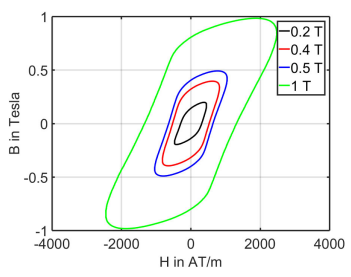

(c)

Fig. 10. B-H loops at $f=50 \mathrm{~Hz}$ for different $B_{p k}$ values for solid material. (a) EN8. (b) EN353 hardened. (c) EN353 nonhardened.

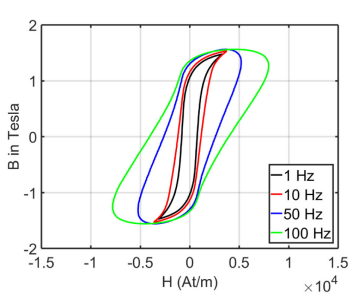

(a)

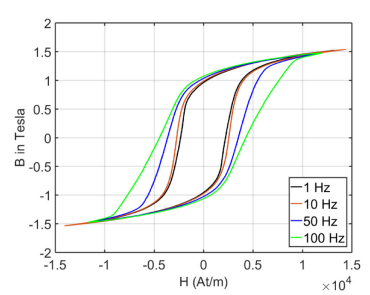

(b)

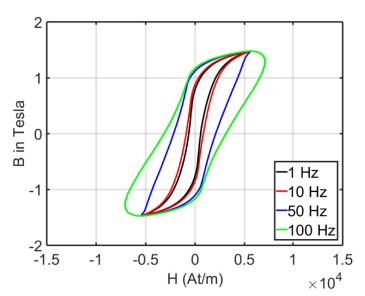

(c)

Fig. 11. B-H loops for $B_{p k}=1.5 \mathrm{~T}$ at different frequencies for solid material. (a) EN8. (b) EN353 hardened. (c) EN353 nonhardened.

\section{B. Solid Cores}

The measured B-H loops for EN8, hardened EN353 and nonhardened EN353 are shown in Fig. 10(a)-(c), respectively. These are shown for different values of $B_{p k}$ up-to $1 \mathrm{~T}$, all at a frequency of $50 \mathrm{~Hz}$.

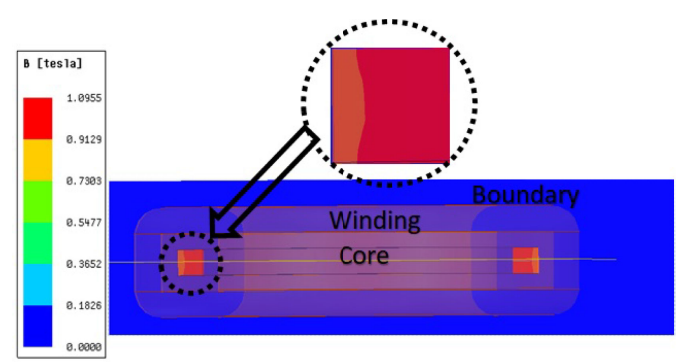

(a)

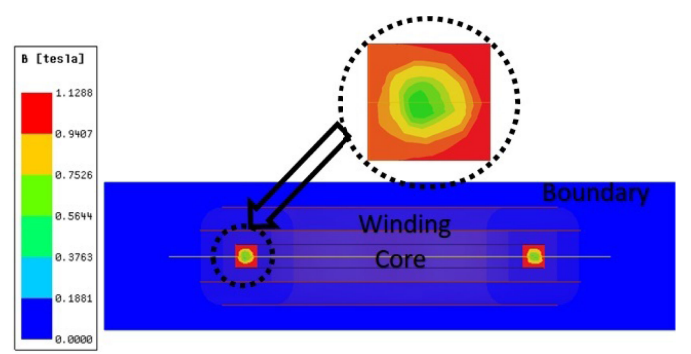

(b)

Fig. 12. Flux density distribution inside the toroidal core for EN8 material obtained through FEA. (a) $10 \mathrm{~Hz}$. (b) $50 \mathrm{~Hz}$.

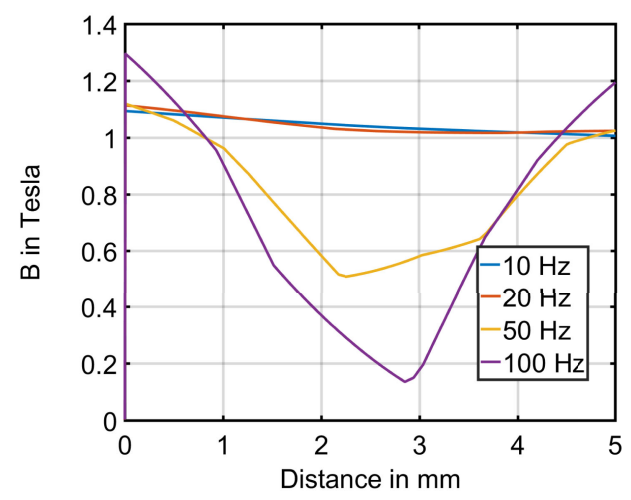

Fig. 13. Flux density versus distance at various frequencies for EN8 solid core obtained through FEA.

As seen from Fig. 10, the loop areas are very high and the B-H loops are nowhere close to the typical "S"-shaped loops. But these loops roughly have the shape of parallelogram with smooth edges. Hardening of material increases the core loss tremendously, as seen by comparing Fig. 10(b) and (c).

At the same $B_{p k}$ of $1.5 \mathrm{~T}$, the B-H loops vary with frequency as shown by Fig. 11(a)-(c), for EN8, hardened EN353 and nonhardened EN353, respectively. Referring to the B-H loops for EN8, in Fig. 11(a), the loops are quite similar for 1 and $10 \mathrm{~Hz}$, but change significantly when the frequency is increased to $50 \mathrm{~Hz}$. This is true for the loops in Fig. 11(b) and (c) as well. Here again, the loop at $50 \mathrm{~Hz}$ is quite different from those at 1 and $10 \mathrm{~Hz}$. This is investigated through FEA below.

The result of FE analysis of sample 8 (EN8 core, 300 turns), when excited at $10 \mathrm{~Hz}$ is shown by Fig. 12(a). The large rectangle in the figure includes a cross section of the toroidal core along 


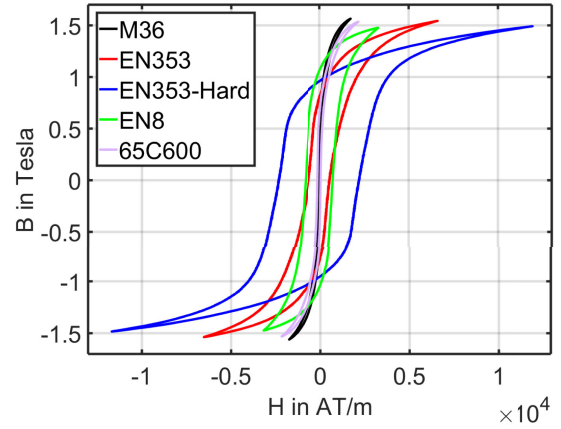

Fig. 14. B-H loops of all the materials at $1 \mathrm{~Hz}$ frequency and $1.5 \mathrm{~T}$ peak flux density.

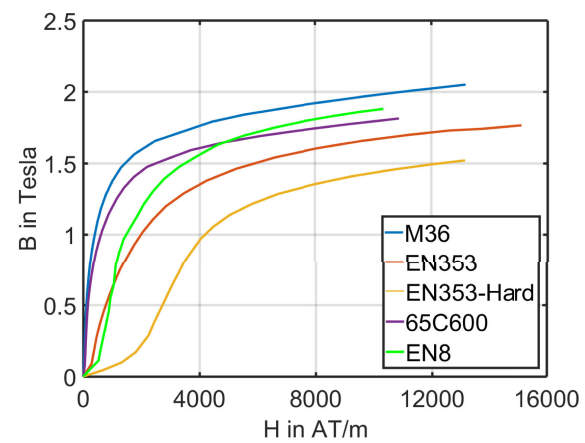

Fig. 15. Static magnetisation curves for different materials.

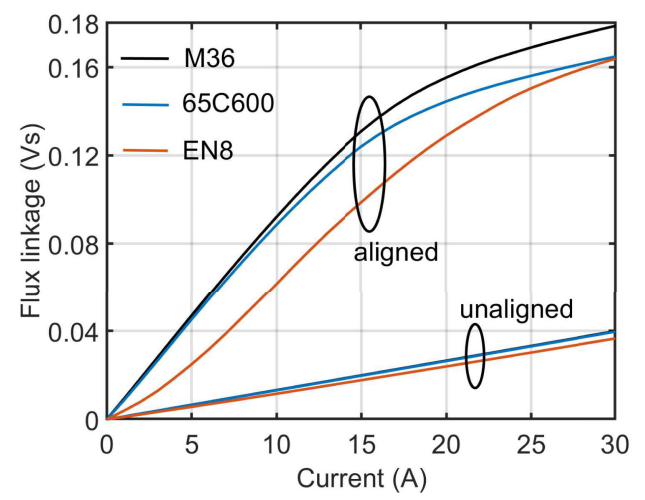

Fig. 16. Static flux linkage characteristics of an SRM at aligned and unaligned position using different materials.

with the coils. One can see that the flux density is high only within the core. The flux density in the core is shown expanded in the same figure. As seen, the flux density is uniform at around $1.1 \mathrm{~T}$ throughout the cross section. However, when the excitation frequency is increased to $50 \mathrm{~Hz}$, the core flux density is nonuniform as indicated by Fig. 12(b). The flux density is high at the edges of the core and reduces inside.

The variation of flux density across the cross section of the core is shown by Fig. 13. This is shown for excitation frequencies

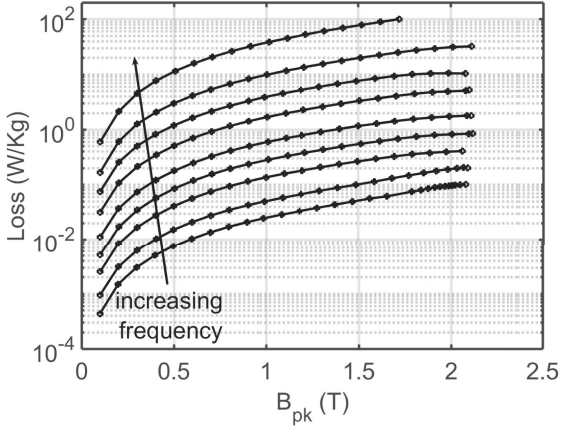

(a)

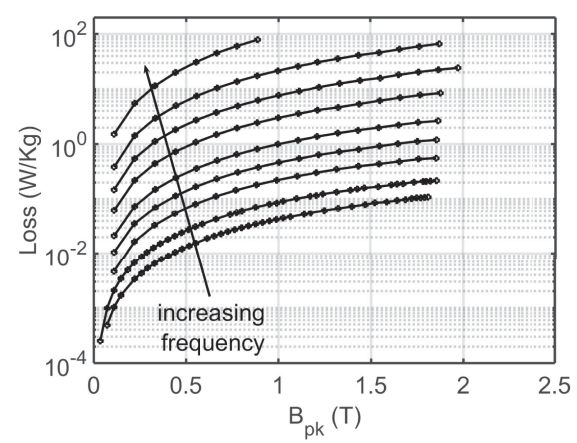

(b)

Fig. 17. Power Loss curves at frequencies $f=1,2,5,10,20,50,100,200$, and $500 \mathrm{~Hz}$ for laminated material. (a) M36. (b) 65C600.

TABLE III

CORE LOSS PARAMETERS FOR M36 AND 65C600 LAMINATION MATERIALS (TILL $500 \mathrm{~Hz}$ )

\begin{tabular}{c|c|c} 
& M36 & $65 \mathrm{C} 600$ \\
\hline$\alpha$ & 1.593 & 1.607 \\
$k_{h y}$ & 0.025 & 0.04 \\
$k_{e d}$ & $6.87 \times 10^{-5}$ & $2.8 \times 10^{-4}$ \\
$k_{e x}$ & $7.12 \times 10^{-4}$ & $6.42 \times 10^{-4}$
\end{tabular}

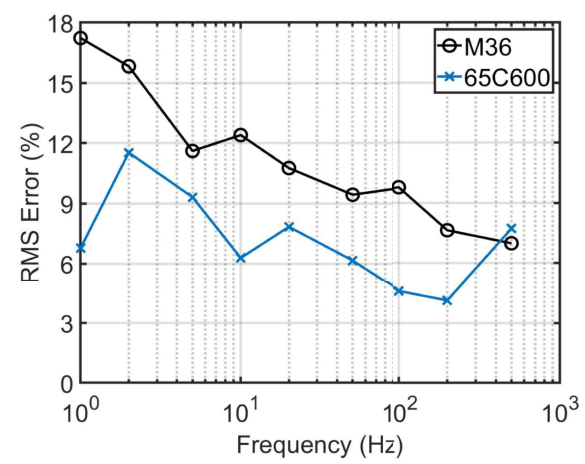

Fig. 18. Normalized rms error between estimated and measured power loss.

of $10,20,50$, and $100 \mathrm{~Hz}$. The $B$ versus distance is flat for 10 and $20 \mathrm{~Hz}$, it starts varying above $20 \mathrm{~Hz}$. Consequently, the effective core cross-section area decreases above $20 \mathrm{~Hz}$ in these cases. 


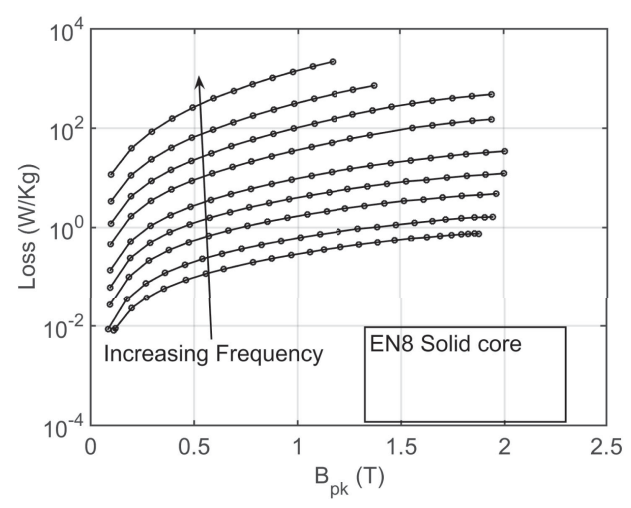

(a)

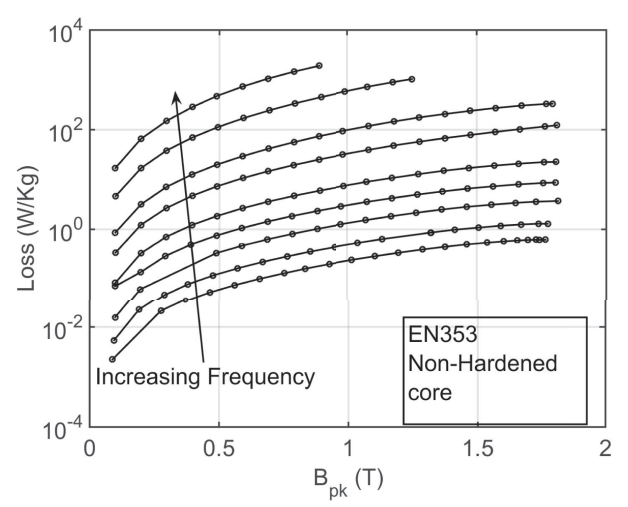

(b)

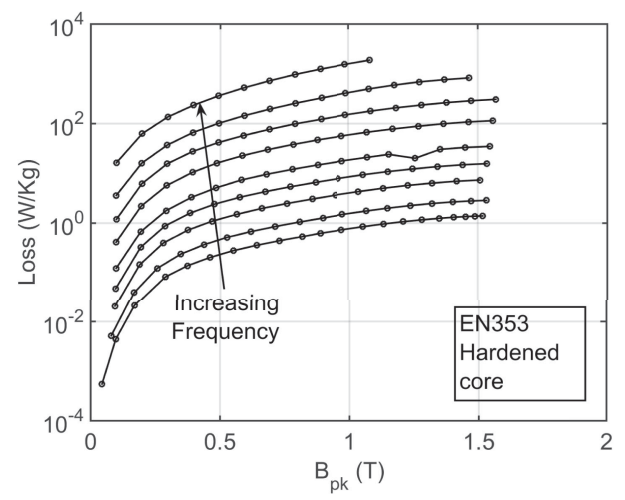

(c)

Fig. 19. Power loss curves at frequencies $f=1,2,5,10,20,50,100,200$, and $500 \mathrm{~Hz}$ for solid core material. (a) EN8. (b) EN353 nonhardened. (c) EN353 hardened.

\section{Comparison of Magnetic Materials}

Fig. 14 compares the B-H loops of all five materials at $B_{p k}=$ $1.5 \mathrm{~T}$ and $f=50 \mathrm{~Hz}$. The $H_{p k}$ values are very low for laminated materials (M36, 65C600), but are high for solid cores. The $H_{p k}$ value is the highest for hardened EN353.

The static magnetization curves of the materials are compared in Fig. 15. Saturation is evident in all curves. The permeability is quite high for M36, and the degree of saturation at high $B$ is also quite high. EN8 and hardened EN353 have nonlinear behavior at low $B$ as well. The impact of these magnetic material

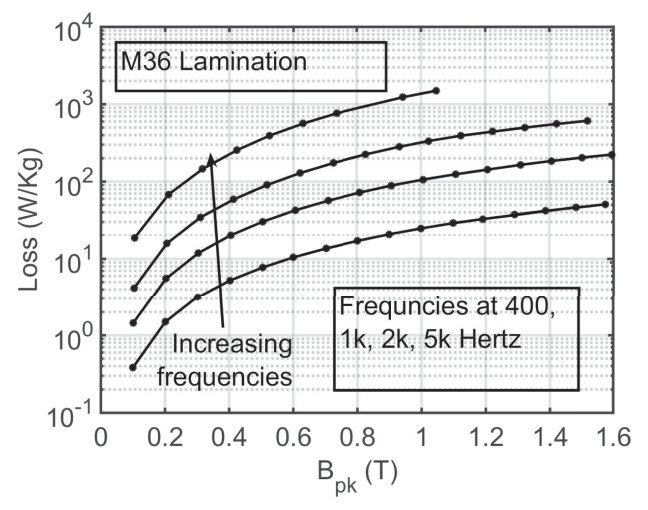

(a)

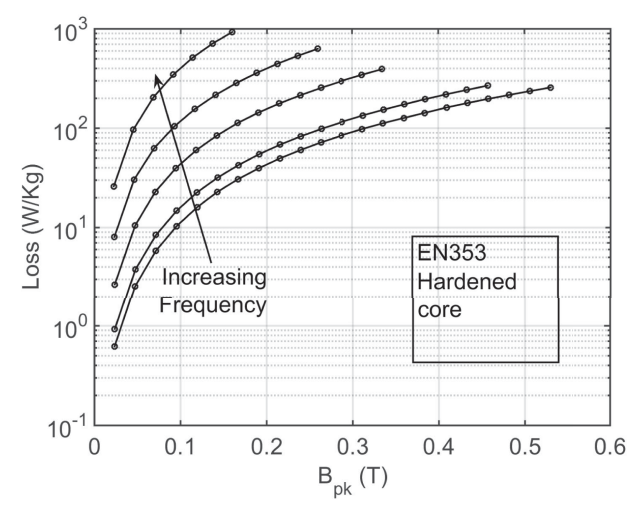

(b)

Fig. 20. Power Loss curves at high frequencies. (a) M36 lamination (at 0.4, 1,2 , and $5 \mathrm{kHz}$ ). (b) EN353 hardened core (at $0.4,0.5,1,2$, and $5 \mathrm{kHz}$ ).

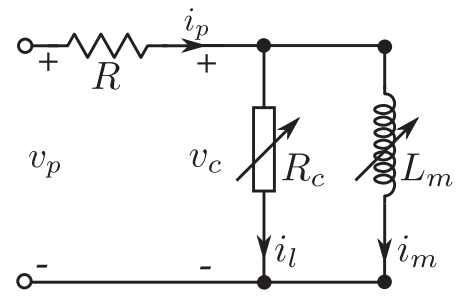

Fig. 21. Equivalent circuit of a winding having large core-loss [31].

characteristics on the performance of a switched reluctance motor (SRM) is demonstrated in the following section.

\section{Impact on Motor Performance}

Considering an SRM of dimensions as reported in [31], the flux-linkage characteristics are evaluated through FEA. Both stator and rotor cores are considered to be constructed of the same material. When the magnetic material is changed, the stator flux-linkage characteristic in the unaligned position of the rotor [40] is changed slightly, as shown by Fig. 16. However, as should be expected, the flux-linkage characteristic in the aligned rotor position [40] is impacted highly by the choice of magnetic material, as evident from Fig. 16.

The area enclosed between the aligned and unaligned fluxlinkage characteristics is a measure of torque output of the 


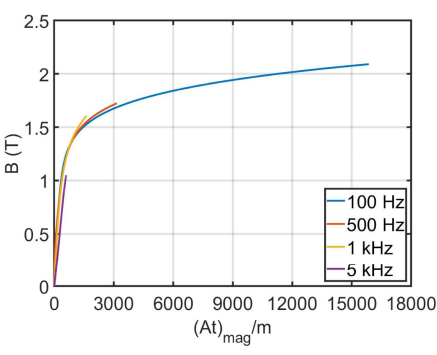

(a)

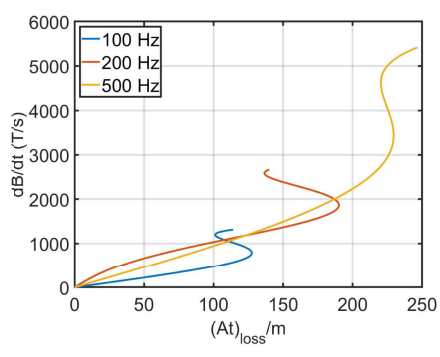

(b)

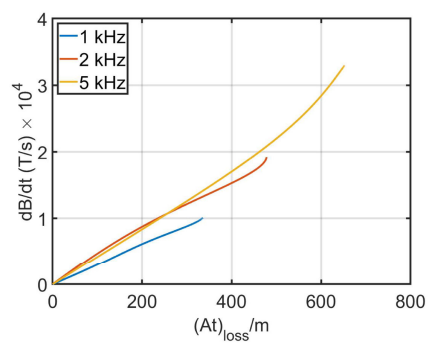

(c)

Fig. 22. Magnetizing and loss characteristics of M36 material. (a) Magnetization characteristics $100 \mathrm{~Hz}$ to $5 \mathrm{kHz}$. (b) Core-loss characteristics 100 to $500 \mathrm{~Hz}$. (c) Core-loss characteristics 1 to $5 \mathrm{kHz}$.

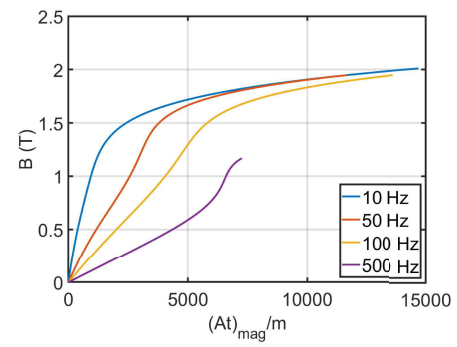

(a)

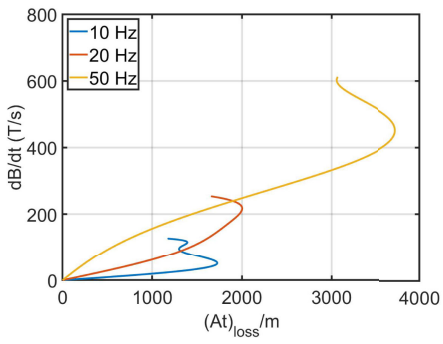

(b)

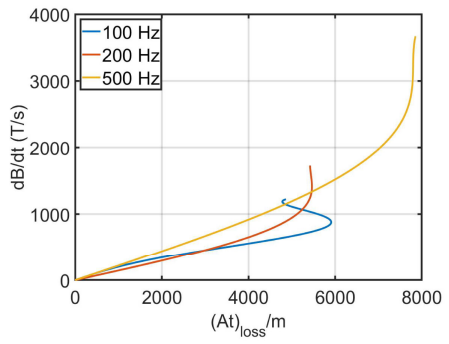

(c)

Fig. 23. Magnetizing and loss characteristics of EN8 material. (a) Magnetization characteristics 10 to $500 \mathrm{~Hz}$. (b) Core-loss characteristics 10 to $50 \mathrm{~Hz}$. (c) Core-loss characteristics 100 to $500 \mathrm{~Hz}$.

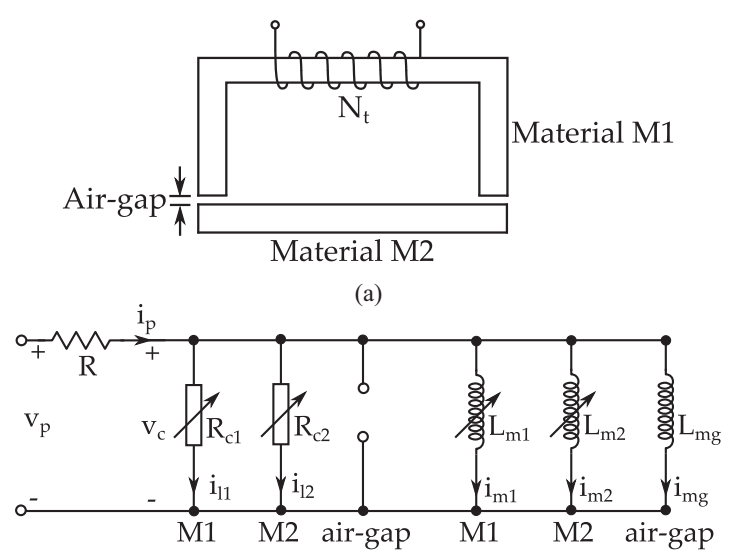

(b)

Fig. 24. Equivalent circuit for a core with different materials. (a) Geometry. (b) Equivalent circuit.

motor [40]. The reduction in torque output, due to the inevitable usage of a material such as EN8 to realize a motor for harsh operating conditions [31], can be evaluated by the motor designer, based on the experimental data in the previous sections. The experimental procedure and data are thus helpful to evaluate the various magnetic-material-dependent characteristics and performance parameters of the motor.

\section{POWER LOSS CURVES}

The power loss is evaluated based on the measured voltage and current waveforms as discussed in Section II-G. The loss in $\mathrm{W} / \mathrm{kg}$, evaluated at different values of $B_{p k}$ and frequencies, for M36 and 65C600 laminations are presented in Fig. 17(a) and (b), respectively. These results are reported for a frequency range of 1 to $500 \mathrm{~Hz}$ in the figures. The experimental results tally with the data sheet values, which are available only at specific frequency $(50 \mathrm{~Hz})$. At each frequency, the rate of increase in loss/kg with $B_{p k}$ reduces with increase in $B_{p k}$ for both materials. For the frequency range of 1 to $500 \mathrm{~Hz}$, the experimental data can be fitted into the following relationship [41] with reasonable accuracy.

$$
P_{d}=k_{h y} B_{p k}^{\alpha} f+k_{e d} B_{p k}^{2} f^{2}+k_{e x} B_{p k}^{1.5} f^{1.5}
$$

where $k_{h y}, k_{e d}$, and $k_{e x}$ are the hysteresis, eddy current, and excess loss coefficients, respectively. The values of these coefficients and the exponent $\alpha$ in (5) are tabulated in Table III. The rms error between the experimental curve and the fitted curve is evaluated at each frequency as shown below:

$$
\operatorname{Rms} \text { error }(\%)=\frac{1}{N} \sqrt{\frac{P_{d}-P_{\mathrm{mod}}}{P_{d}}} \times 100
$$

where $N$ is the number of data points at each frequency. The rms error is shown plotted for both materials in Fig. 18.

The power loss density curves for EN8, hardened EN353 and non-hardened EN353 are shown in Fig. 19(a)-(c), respectively. In these two figures, experimental results are reported at different $B_{p k}$ values and up-to $500 \mathrm{~Hz}$ excitation frequency. The solid core materials have much higher losses due to large eddy current losses. For the considered $5 \mathrm{~mm}$ depth of toroidal core, the losses in case of solid material increase rapidly beyond $50 \mathrm{~Hz}$. 


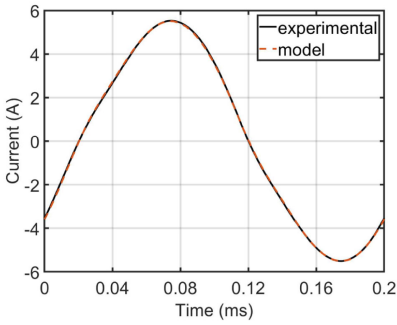

(a)

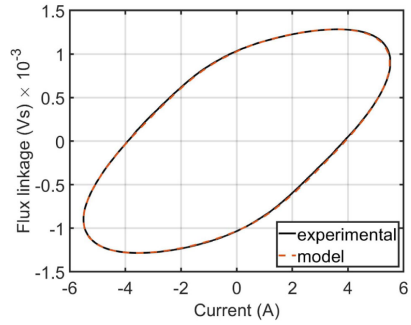

(b)

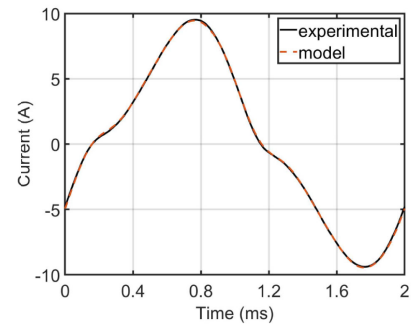

(c)

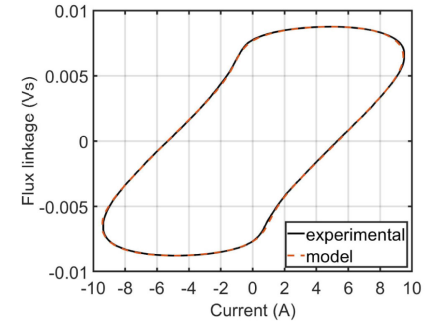

(d)

Fig. 25. Verification of harmonic equivalent circuit. Experimental value and estimation using model are nearly coincident. (a) Measured and estimated winding current at $5 \mathrm{kHz}, \mathrm{M} 36$ material. (b) Measured and estimated flux linkage loop at $5 \mathrm{kHz}$, M36 material. (c) Measured and estimated winding current at $500 \mathrm{~Hz}$, EN8 material. (d) Measured and estimated flux linkage loop at $500 \mathrm{~Hz}$, EN8 material.

Power loss data over a higher frequency range of $400 \mathrm{~Hz}$ to $5 \mathrm{kHz}$ are plotted in Fig. 20(a) and (b). These are obtained for two of the tested materials, namely, M36 lamination and EN353 hardened core.

\section{DETERMinATION OF Winding EQUiVALENT CiRCUIT}

Extending the work in [31], this section proposes a method for determining the equivalent circuit of any winding wound over a core of such magnetic materials. The equivalent circuit is useful to predict the current waveshape drawn by the winding for a given applied voltage.

\section{A. Magnetization and Loss Characteristics of Magnetic Material}

The equivalent circuit of a winding over a magnetic material, which has significantly large B-H loop at a given frequency, can be represented by Fig. 21 [31]. The equivalent circuit consists of a series winding resistance $R$, a variable core-loss resistance $R_{c}$, and a variable magnetizing inductance $L_{m}$ as shown. The voltage $v_{c}$ across the core-loss and magnetizing branches is obtained as the measured $v_{s}$, since number of turns in primary and secondary are equal. Integral of $v_{c}$ yields the flux linkage $\psi$ of the winding. The measured $i_{p}$ is divided into the core-loss branch current $i_{l}$ and magnetizing branch current $i_{m}$ as explained in [31]. The characteristics $\psi$ versus $i_{m}$ and $v_{c}$ versus $i_{l}$ depend on the core geometry and describe the magnetizing and core-loss branches, respectively, of the winding at the given frequency [31].

The flux linkage $\psi$ and voltage $v_{c}$ can be normalized with respect to $N_{p} A$ to obtain $B$ and $d B / d t$, respectively. Similarly the currents $i_{m}$ and $i_{l}$ both can be scaled by $N_{p} / l_{m}$ to obtain $f_{m}$ and $f_{l}$, respectively. These characteristics (i.e., $B$ versus $f_{m}$ and $d B / d t$ versus $f_{l}$ ) are independent of core geometry, and are related to material properties.

These material characteristics for M36 and EN8 are plotted in Figs. 22 and 23. Plot of $B$ versus $f_{m}$ for M36 laminations at different frequencies over the range of $100 \mathrm{~Hz}$ to $5 \mathrm{kHz}$ are shown in Fig. 22(a). As observed, the magnetization characteristics are mostly same even at high frequencies. Plot of $d B / d t$ versus $f_{l}$ are shown for the range 100-500 Hz in Fig. 22(b), and for 1 to $5 \mathrm{kHz}$ in Fig. 22(c). These loss characteristics show a wide variation.
In Fig. 23(a) magnetizing characteristics of EN8 are shown for a frequency range of 10-500 Hz. Fig. 23(b) and (c) shows the loss characteristics, for a frequency range of $10-50 \mathrm{~Hz}$ and $100-500 \mathrm{~Hz}$, respectively. Significant variation with frequency in both magnetizing and loss characteristics can be observed.

\section{B. Winding Equivalent Circuit}

The magnetizing and loss characteristics of the material can be used to determine equivalent circuit parameters of a winding. Consider the geometry shown in Fig. 24(a), comprising of an Ushaped section made of material M1, an I-shaped section made of material M2 and two air gaps. The corresponding equivalent circuit is shown in Fig. 24(b).

The series magnetic paths in the geometry all experience same flux density, and therefore represented by the three parallel branches (material M1, material M2, and air gap) in the equivalent circuit. Magnetizing current $i_{m 1}$ can be obtained using the $B$ versus $f_{m}$ characteristic of material M1 and geometry of the section. Similarly, $i_{m 2}$ can be obtained using the corresponding $B$ versus $f_{m}$ characteristics of material M2 and geometric details. The current $i_{m g}$ corresponding to air gap can be obtained using $f_{m g}=B / \mu_{0}$ characteristics of air and gap dimensions.

The core-loss branch also has parallel paths, corresponding to the three materials in the magnetic circuit. The path corresponding to air gap is open circuit. Currents $i_{l 1}$ and $i_{l 2}$ are obtained from the corresponding loss characteristics of the magnetic material.

\section{Limited Verification}

The measured and estimated current waveform from the model is compared in Fig. 25(a). The winding current of the toroid made of M36 at $5 \mathrm{kHz}$ frequency is plotted. The corresponding measured and estimated flux-linkage loop is shown in Fig. 25(b). The current waveform and the loop shape is accurately estimated by the model. Similar waveforms are compared in Fig. 25(c) and (d) for the toroid made of EN8 material at a frequency of $500 \mathrm{~Hz}$. Here too, accuracy of the model can be verified. The proposed equivalent circuit accurately estimates the time domain winding current at high frequencies. 


\section{CONCLUSION}

Magnetic characteristics of ferromagnetic alloys over a range of $1-5 \mathrm{kHz}$ are obtained experimentally and the procedure for the same is discussed. The ferromagnetic alloys studied are M36, 65C600, EN8, hardened EN353, and nonhardened EN353. M36 and 65C600 are silicon-iron lamination materials, EN8 and E353 are solid carbon steel. The test results of different materials are presented and discussed. It is observed that the current drawn has mostly third and fifth order odd harmonics. The lamination materials have peaky current. The current in case of solid material is less peaky but still distorted. The B-H loops for the lamination materials follow typical "S"-shape, whereas they appear close to parallelogram in solid material. Surface hardening of material significantly increases the B-H loop area in the material. The static magnetization curves are obtained for different test samples. The loss densities are given at different frequencies and for different values of peak flux densities. These results are critical for the analysis, design, and performance evaluation of high-speed machines, which use these ferromagnetic alloys.

\section{ACKNOWLEDGMENT}

The authors would like to thank Precision MachineKraft (P) Ltd, Bengaluru, India and Shakti Pumps, Pithampur, India for their help in fabrication of the toroidal cores.

\section{REFERENCES}

[1] S. Li, Y. Li, W. Choi, and B. Sarlioglu, "High-speed electric machines: Challenges and design considerations," IEEE Trans. Transport. Electrific., vol. 2, no. 1, pp. 2-13, Mar. 2016.

[2] D. Gerada, A. Mebarki, N. L. Brown, C. Gerada, A. Cavagnino, and A. Boglietti, "High-speed electrical machines: Technologies, trends, and developments," IEEE Trans. Ind. Electron., vol. 61, no. 6, pp. 2946-2959, Jun. 2014.

[3] W. Zhao, X. Wang, C. Gerada, H. Zhang, C. Liu, and Y. Wang, "Multiphysics and multi-objective optimization of a high speed PMSM for high performance applications," IEEE Trans. Magn., vol. 54, no. 11, pp. 1-5, Nov. 2018.

[4] P. Chen, J. Chen, Y. Liao, C. Zhang, and J. Du, "Vibration and noise of high speed amorphous alloy permanent magnet synchronous motor," in Proc. Int. Conf. Elect. Mach. Syst., Oct. 2018, pp. 318-322.

[5] H. Fang, R. Qu, J. Li, P. Zheng, and X. Fan, "Rotor design for high-speed high-power permanent-magnet synchronous machines," IEEE Trans. Ind. Appl., vol. 53, no. 4, pp. 3411-3419, Jul. 2017.

[6] Y. Huang, J. Zhu, and Y. Guo, "Thermal analysis of high-speed SMC motor based on thermal network and 3-D FEA with rotational core loss included," IEEE Trans. Magn., vol. 45, no. 10, pp. 4680-4683, Oct. 2009.

[7] S. P. Verma and A. Balan, "Measurement techniques for vibration and acoustic noise of electrical machines," in Proc. Int. Conf. Elect. Mach. Drives, Sep. 1993, pp. 546-551.

[8] B. A. Kumar and G. Narayanan, "A low-cost system for measurement and spectral analysis of motor acoustic noise," in Proc. Nat. Power Eletron. Conf., 2001, pp. 24-29.

[9] A. C. Binojkumar, B. Saritha, and G. Narayanan, "Acoustic noise characterization of space-vector modulated induction motor drives an experimental approach," IEEE Trans. Ind. Electron., vol. 62, no. 6, pp. 3362-3371, Jun. 2015.

[10] S. Narchail et al., "Experimental investigations on a high-speed rotor for a switched reluctance machine," in Proc. IEEE India Int. Conf. Power Electron., Dec. 2018, pp. 1-6.

[11] R. T. Fingers and C. S. Rubertus, "Application of high temperature magnetic materials," IEEE Trans. Magnet., vol. 36, no. 5, pp. 3373-3375, Sep. 2000
[12] J. Faiz, B. Ganji, C. E. Carstensen, K. A. Kasper, and R. W. De Doncker, "Temperature rise analysis of switched reluctance motors due to electromagnetic losses," IEEE Trans. Magn., vol. 45, no. 7, pp. 2927-2934, Jul. 2009.

[13] M. Wcislik and K. Suchenia, "Analysis of the influence of material parameters on efficiency of switched reluctance motor," in Proc. Conf. Electrotechnol. Processes, Models, Control Comput. Sci., Nov. 2018, pp. $1-5$.

[14] H. Toda, K. Senda, S. Morimoto, and T. Hiratani, "Influence of various non-oriented electrical steels on motor efficiency and iron loss in switched reluctance motor," IEEE Trans. Magn., vol. 49, no. 7, pp. 3850-3853, Jul. 2013.

[15] E. Dlala, "A simplified iron loss model for laminated magnetic cores," IEEE Trans. Magn., vol. 44, no. 11, pp. 3169-3172, Nov. 2008.

[16] M. Fratila, A. Benabou, A. Tounzi, and M. Dessoude, "Calculation of iron losses in solid rotor induction machine using FEM," IEEE Trans. Magn., vol. 50, no. 2, pp. 825-828, Feb. 2014.

[17] V. Raulin, A. Radun, and I. Husain, "Modeling of losses in switched reluctance machines," IEEE Trans. Ind. Appl., vol. 40, no. 6, pp. 1560-1569, Nov. 2004.

[18] P. N. Materu and R. Krishnan, "Estimation of switched reluctance motor losses," IEEE Trans. Ind. Appl., vol. 28, no. 3, pp. 668-679, May 1992.

[19] V. J. Thottuvelil, T. G. Wilson, and H. A. Owen, "High-frequency measurement techniques for magnetic cores," in Proc. IEEE Power Electron. Specialists Conf., Jun. 1985, pp. 412-425.

[20] Z. Shi et al., "High speed characterization of the magnetoelectric hysteresis loop," IEEE Trans. Magn., vol. 49, no. 12, pp. 5671-5674, Dec. 2013.

[21] J. H. J. Potgieter, F. J. Mrquez-Fernndez, A. G. Fraser, and M. D McCulloch, "Effects observed in the characterization of soft magnetic composite for high frequency, high flux density applications," IEEE Trans. Ind. Electron., vol. 64, no. 3, pp. 2486-2493, Mar. 2017.

[22] JFE steel Corporation, "Electrical steel sheets," 2009. [Online]. Available: http://www.jfe-steel.co.jp/en/products/electrical/index.php

[23] Thyssenkrupp, "Powercore electrical steel," 2009. [Online]. Available: http://www.tkesindia.com/our_products.pdf

[24] Y. Oda, H. Toda, N. Shiga, S. Kasai, and T. Hiratani, "Effect of Si content on iron loss of electrical steel sheet under compressive stress," IEEE Trans. Magn., vol. 50, no. 4, pp. 1-4, Apr. 2014.

[25] R. Kolano, K. Krykowski, A. Kolano-Burian, M. Polak, J. Szynowski, and P. Zackiewicz, "Amorphous soft magnetic materials for the stator of a novel high-speed PMBLDC motor," IEEE Trans. Magn., vol. 49, no. 4, pp. 1367-1371, Apr. 2013

[26] A. G. Torres, B. J. C. Filho, R. O. C. Lyra, M. A. Cunha, and S. C. Paolinelli, "Determination of the magnetic losses in induction motors based on the generalized epstein test," in Proc. IEEE Ind. Appl. Conf., Oct. 2004, vol. 1, Art. no. 8.

[27] A. S. L. Costa, R. R. Bastos, S. C. Paolinelli, S. L. Nau, R. M. Valle, and B. J. C. Filho, "A critical analysis of standard methods for characterization of electrical steels: Losses in high speed induction motors," in Proc. IEEE Ind. Appl. Soc. Annu. Meeting, Oct. 2014, pp. 1-8.

[28] D. Miyagi, N. Maeda, Y. Ozeki, K. Miki, and N. Takahashi, "Estimation of iron loss in motor core with shrink fitting using FEM analysis," IEEE Trans. Magn., vol. 45, no. 3, pp. 1704-1707, Mar. 2009.

[29] K. Yamazaki, K. Tanaka, and M. Ohto, "Impact of core material grades on performance of variable speed induction motors fed by inverters," in Proc. IEEE Ener. Convers. Cong. Expo., Oct. 2017, pp. 286-292.

[30] C. Steel Corporation, "Electrical steel sheets," 2016. [Online]. Available: https://www.csc.com.tw/csc/pd/doc/spec_es_e_2016.pdf

[31] S. S. Ahmad and G. Narayanan, "Experimental investigations on flux linkage characteristics and stator-side modeling of a solid-rotor switched reluctance machine," IEEE Trans. Ind. Electron., vol. 67, no. 12, pp. 10180-10190, Dec. 2020.

[32] J. Pyrhonen, J. Nerg, P. Kurronen, and U. Lauber, "High-speed high-output solid-rotor induction-motor technology for gas compression," IEEE Trans. Ind. Electron., vol. 57, no. 1, pp. 272-280, Jan. 2010.

[33] X. Ba, Y. Guo, J. Zhu, and C. Zhang, "An equivalent circuit model for predicting the core loss in a claw-pole permanent magnet motor with soft magnetic composite core," IEEE Trans. Magn., vol. 54, no. 11, pp. 1-6, Nov. 2018

[34] T. Sato and Y. Sakaki, "Physical meaning of equivalent loss resistance of magnetic cores," IEEE Trans. Magn., vol. 26, no. 5, pp. 2894-2897, Sep. 1990. 
[35] F. J. Perez-Cebolla, A. Martinez-Iturbe, B. Martn-del-Bro, C. Bernal, and A. Bono-Nuez, "Nonlinear lumped-circuit model for switched reluctance motors exhibiting core losses," IEEE Trans. Ind. Electron., vol. 63, no. 6, pp. 3433-3445, Jun. 2016.

[36] C. Urabinahatti, S. S. Ahmad, and G. Narayanan, "Magnetic characterization of ferromagnetic alloys for high speed electric machines," in Proc. IEEE Int. Conf. Power Electron., Drives Energy Syst., Dec. 2018, pp. 1-5.

[37] C.-J. Wu, S.-Y. Lin, S.-C. Chou, C.-Y. Tsai, and J.-Y. Yen, "Temperature effects on the magnetic properties of silicon-steel sheets using standardized toroidal frame," Sci. World J., vol. 2014, 2014, Art. no. 975051.

[38] J. T. Charton, J. Corda, A. Hughes, J. M. Stephenson, and S. P. Randall, "Iron loss measurement technique and experience for flux including dc offsets," in Proc. Eur. Conf. Power Electron. Appl., 2005, Art. no. 8.

[39] A. Dauhajre and R. D. Middlebrook, "Modelling and estimation of leakage phenomena in magnetic circuits," in Proc. Annu. IEEE Power Electron. Specialists Conf., 1986, pp. 213-226.

[40] T. J. E. Miller, Electronic Control of Switched Reluctance Machine (Newnes Power Engineering Series). Amsterdam, The Netherlands: Elsevier, 2001.

[41] D. Eggers, S. Steentjes, and K. Hameyer, "Advanced iron-loss estimation for nonlinear material behavior," IEEE Trans. Magn., vol. 48, no. 11, pp. 3021-3024, Nov. 2012

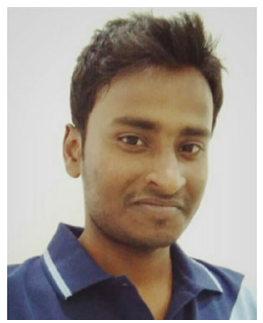

Chetan Urabinahatti received the B.E. degree in electrical engineering from the Gogte Institute of Technology, Belgaum, India, in 2013, and the M.Tech. degree in electrical engineering from the Malnad College of Engineering, Hassan, India, in 2015.

$\mathrm{He}$ is currently working as a Project Associate with the Department of Electrical Engineering, Indian Institute of Science Bangalore, Bengaluru, India His research interests include thermal management of power electronic converters, electric machines, and magnetic materials for electric machines.

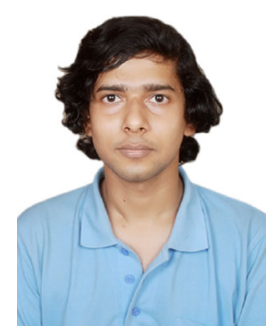

Syed Shahjahan Ahmad received the B.E. degree in electrical engineering from the Indian Institute of Engineering Science and Technology, Shibpur, India, in 2012, and the M.E. degree in 2014 in electrical engineering from the Indian Institute of Science Bangalore, Bengaluru, India, where he is currently working toward the Ph.D. degree in electrical engineering with the Department of Electrical Engineering.

His research interests include design and control of switched reluctance machines, high-speed electric drives, power electronic converters, and modeling and control of power electronic systems.

Syed Shahjahan Ahmad was the recipient of Nampet-II Student Project Award for his master's work from Dept. of Electronics and Information Technology, Govt. of India in 2014.

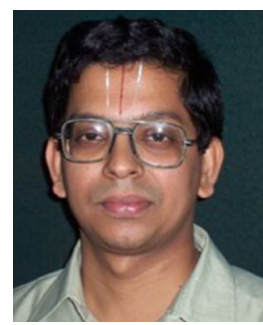

Gopalaratnam Narayanan received the B.E. degree from Anna University, Chennai, India, in 1992, the M.Tech. degree from the Indian Institute of Technology, Kharagpur, Kharagpur, India, in 1994, and the $\mathrm{Ph} . \mathrm{D}$. degree from the Indian Institute of Science, Bangalore Bengaluru, India, in 2000, all in electrical engineering.

$\mathrm{He}$ is currently a Professor and Chair of the Department of Electrical Engineering, Indian Institute of Science. His research interests include ac drives, active rectifiers, electric machines, multilevel inverters, power semiconductor devices, and pulsewidth modulation.

Dr. Narayanan was the recipient of the Innovative Student Project Award for his Ph.D. work from the Indian National Academy of Engineering in 2000, the Young Scientist Award from the Indian National Science Academy in 2003, the Microsoft Research (India) Outstanding Young Faculty Award in 2010, the Bimal Bose Award from the Institution of Electronics and Telecommunication Engineers (India) in 2013, and the Karnataka State Prof. Satish Dhawan Young Engineer Award (India) in 2014. 